\title{
What type of worker are you? Work-related Inventory (WI-10): A comprehensive instrument for the measurement of workaholism
}

\author{
Yura Loscalzo* and Marco Giannini \\ Department of Health Sciences, School of Psychology, University of Florence, Florence, Italy
}

Received 6 November 2017

Accepted 3 August 2018

\begin{abstract}
.
BACKGROUND: In literature, there are many instruments for evaluating workaholism; however, they do not have convergent validity, because of the lack of a shared definition of workaholism.

OBJECTIVE: We propose a new instrument for evaluating workaholism and work engagement, namely the Work-related Inventory (WI-10), which is based on Loscalzo and Giannini's (2017) comprehensive definition of workaholism.

METHODS: We developed a pool of 36 items, covering: 1) addiction symptoms; 2) obsessive-compulsive symptoms, and 3 ) work engagement. Then, we conducted Exploratory and Confirmatory Factor analyses on a sample of 503 Italian workers ( 165 males, 337 females, one missing; Mean age $=38.26 \pm 10.84$ ) aiming to reduce the number of items.

RESULTS: The results showed a 10-items (2 filler) and 2-factor solution: 1) Workaholism and 2) Work Engagement; moreover, the WI-10 has good internal reliability, convergent and divergent validity.

CONCLUSIONS: We found good psychometric properties for the WI-10. We also proposed the cut-off scores for the screening of the four kinds of workers proposed by Loscalzo and Giannini (2017): disengaged workaholics, engaged workaholics, engaged workers, and detached workers. The WI-10 will be useful for both research and preventive and clinical purposes.
\end{abstract}

Keywords: Heavy work investment, organizations, screening, well-being, work addiction, work engagement

\section{Introduction}

Scholars have analyzed work in many aspects, such as the psychological health and well-being associated to jobs characterized by high stress, like those of military personnel (e.g., [1-3]) and healthcare professionals (e.g., [4-6]). Moreover, many researchers have been interested in the effects of the ergonomic and structural aspects of the job (e.g., [7-9]) and the influence that physical and mental health problems may have on work (e.g., [10-12]).

\footnotetext{
*Address for correspondence: Yura Loscalzo, Department of Health Sciences, School of Psychology, University of Florence, Via di San Salvi 12 - Padiglione 26, 50135 Florence, Italy. Tel.: +39055 275507; E-mail: yura.loscalzo@gmail.com.
}

Among the various work-related aspects widely studied, there is also workaholism, a construct coined by Oates [13] in 1971 for defining a worker who feels the compulsion to work incessantly and whose behavior results in health and social functioning impairment.

Since Oates' [13] first definition, many researchers studied this problematic behavior. However, a definition shared by the scientific community is still lacking, and there is a great need for a unique definition that could allow a cumulative knowledge of the phenomenon. Currently, there are many conceptualizations of workaholism, as well as many instruments for its assessment (see Table 1 for a review of the instruments presented so far for 
Table 1

Workaholism measures

\begin{tabular}{|c|c|c|}
\hline Name & Authors & Subscales \\
\hline Workaholism Battery (WorkBat) & Spence \& Robbins, 1992 & $\begin{array}{l}\text { 1) Work Drive } \\
\text { 2) Work Involvement } \\
\text { 3) Work Enjoyment }\end{array}$ \\
\hline Work Addiction Risk Test (WART) & Robinson, 1989 & $\begin{array}{l}\text { 1) Compulsive Tendencies } \\
\text { 2) Control } \\
\text { 3) Impaired Communications/Self-Absorption } \\
\text { 4) Inability to Delegate } \\
\text { 5) Self-Worth }\end{array}$ \\
\hline $\begin{array}{l}\text { Dutch Work Addiction Scale } \\
\text { (DUWAS) }\end{array}$ & Schaufeli et al., 2009 & $\begin{array}{l}\text { 1) Working Compulsively } \\
\text { 2) Working Excessively }\end{array}$ \\
\hline $\begin{array}{l}\text { Bergen Work Addiction Scale } \\
\text { (BWAS) }\end{array}$ & Andreassen et al., 2012 & None. Total score only \\
\hline $\begin{array}{l}\text { Workaholism Analysis Questionnaire } \\
\text { (WAQ) }\end{array}$ & Aziz et al., 2013 & $\begin{array}{l}\text { 1) Work-Life Conflict } \\
\text { 2) Work Perfectionism } \\
\text { 3) Work Addiction } \\
\text { 4) Unpleasantness } \\
\text { 5) Withdrawal Symptoms }\end{array}$ \\
\hline Work Craving Scale (WCS) & Wojdylo et al., 2013 & $\begin{array}{l}\text { 1) Obsessive-Compulsive Desire for Work } \\
\text { 2) Anticipation of Self-Worth Compensatory Incentives from Work } \\
\text { 3) Anticipation of Reduction of Negative Affect (Relief) and } \\
\text { Withdrawal Symptoms } \\
\text { 4) Neurotic Perfectionism }\end{array}$ \\
\hline $\begin{array}{l}\text { Workaholism Facet-Based Scale } \\
\text { (WFBS) }\end{array}$ & Shkoler et al., 2018 & $\begin{array}{l}\text { Two facets: } \\
\text { 1) Modalities of Workaholism } \\
\text { 2) Resources of Workaholism }\end{array}$ \\
\hline
\end{tabular}

evaluating workaholism), which seem to refer to different phenomena [14]. Three of the most used workaholism measures, namely the Workaholism Battery (WorkBat) [15], the Work Addiction Risk Test (WART) [16], and the Dutch Work Addiction Scale (DUWAS), [17] did not show convergent validity [18]. In line with this, a meta-analysis conducted in 2012 by Patel, Bowler, Bowler, and Methe [19] showed that the WorkBat and the WART have different correlations with the work-related variables they analyzed.

Given these issues related to the lack of a shared definition, Loscalzo and Giannini [20] developed a theoretic model of workaholism that comprehends the three main components of this construct: externalizing symptoms (i.e., addiction symptoms), internalizing symptoms (i.e., obsessive-compulsive symptoms), and work engagement.

We believe that a test inclusive of these three dimensions could be of great significance since it could encompass all the components highlighted by different conceptualizations of workaholism, hence providing a general framework for future research.

This test could further develop an instrument that has been proposed recently, that is the Bergen Work Addiction Scale (BWAS) [21]. The BWAS has the merit to refer to a straightforward theory, namely to the addiction theory: it comprehends seven items that address the seven core components of addiction (i.e., salience, tolerance, mood modification, relapse, withdrawal, conflict, problems). However, the BWAS was constructed without taking into account internalizing symptoms (there were 14 potential items in the initial pool of items, namely two for each addiction component). There is an item for cognitive salience, which could be related to an obsessive symptom. However, there were no items related to other internalizing symptoms (such as perfectionism), or items explicitly addressing obsessions, in neither the final test nor the initial pool of items.

We believe, in line with Kardefelt-Winther [22] and Loscalzo and Giannini [20], that we should go beyond a-priori assumptions of addiction when proposing a new potential behavioral addiction, as to identify the real manifestation of the problem behavior. We speculate that this could be suitable for workaholism too. Indeed, even if it is not a new behavioral addiction, it does not have a precise and shared definition yet. Hence, we suggest that we should do a step back and test a definition also based on other potential significant components of workaholism, such as internalizing features and work engagement. 
As regard to work engagement, Loscalzo and Giannini [20] recommended evaluating the possibility to include it as part of the definition of workaholism since Van Beek, Taris, and Schaufeli [23], crossing work engagement and workaholism, found two different kinds of workaholics: disengaged and engaged workaholics. Moreover, Spence and Robbins [15] created a test that evaluates the presence of work enjoyment, which is not the same construct of work engagement, but that is a positive dimension as well. More specifically, through the WorkBat, they evaluated three components: Work Involvement, Work Drive, and Work Enjoyment. They also found six kinds of workers: Workaholic (high on Work Involvement and Work Drive, low on Work Enjoyment); Enthusiastic Workaholic (high on all the three components); Work Enthusiastic (high on Work Involvement and Work Enjoyment, low on Work Drive); Unengaged Worker (low on all the three dimensions); Relaxed Worker (low on Work Involvement and Work Drive, high on Work Enjoyment); Disenchanted Worker (low on Work Involvement and Work Enjoyment, high on Work Drive) [15]. However, further studies did not support the three-factor structure of the WorkBat (e.g., [24, 25]) and this could be the reason why the idea of a positive dimension in workaholism has been dropped.

Nevertheless, since van Beek et al.'s [23] findings support the presence of a positive dimension also in workaholism, we think that we should also evaluate the work engagement component. This factor should comprehend vigor, dedication, and absorption (as defined by Scahufeli, Salanova, González-Romá, \& Bakker [26]), but also work enjoyment. We believe that it is essential to add this positive component in our initial pool of items since it could allow the distinction between disengaged workaholics and engaged workaholics, which could differ concerning both negative outcomes and antecedents [20, 23, 27].

In summary, we aim to evaluate the psychometric properties of the Work-related Inventory (WI-10), which is a test that we created based on Loscalzo and Giannini's [20] comprehensive definition of workaholism as a two-factor construct characterized by (1) externalizing (i.e., addiction) and internalizing (i.e., obsessive-compulsive) symptoms, and by (2) high or low level of work engagement. Since the WI-10 allows detecting four types of workers (disengaged workaholic, engaged workaholic, engaged worker, detached worker), it will favor the implementation of preventive and clinical interventions that are tailored on the worker and, hence, that are effective in increasing work engagement and reducing workaholism.

It is essential screening for workaholism in the organizations since this clinical condition is associated to adverse consequences that are evident at both an individual and situational level, as recently highlighted by Loscalzo and Giannini's review [20]. More specifically, at an individual level, workaholism is associated to both psychological and physical consequences, such as higher stress, sleep problems, depressive mood, disabling back pain, lower job satisfaction, and work-family conflict (hence affecting the workaholic's family also). Among the organizational/situational outcomes of workaholism, there is lower work performance, greater absence due to sickness, aggressive workplace behaviors, and less organizational citizenship behavior [20]. Hence, detecting workers at-risk of workaholism or characterized by high levels of workaholism is critical, as this allows developing preventive and clinical interventions that will positively affect the individual, but also his family and his organization.

\section{Method}

\subsection{Participants}

This study was comprised of 503 Italian workers (165 males, 337 females, and one missing) aged between 19 and 72 years $(\mathrm{M}=38.26$; $\mathrm{SD}=10.84)$.

First, to reduce the number of items of the pilot test, we recruited 203 Italian workers (64 males and 139 females) aged between 19 and 63 years $(M=35.52$; $\mathrm{SD}=9.68$ ) and living in various cities, with Tuscany being the region most represented $(72.4 \%)$. Then, to conduct Confirmatory Factor Analyses, we recruited a sample of 300 Italian workers (101 males, 198 females, one missing) aged between 20 and 72 years $(\mathrm{M}=40.12 ; \mathrm{SD}=11.20)$, all living in Tuscany. See Table 2 for more information about the samples.

\subsection{Materials}

\subsubsection{Work-related Inventory (WI)}

After a reading test with some workers (for having feedback about the comprehensibility of the items), we administered the preliminary version of the test to the first sample of participants. The pilot version was made of eight open-questions asking for the level of school education and working habits (such as working hours per week) and of 36 items 
Table 2

Work-related characteristics of the participants $(n=503)$

\begin{tabular}{|c|c|c|c|}
\hline & & $\begin{array}{l}\text { Sample } 1 \\
(n=203)\end{array}$ & $\begin{array}{r}\text { Sample } 2 \\
(n=300)\end{array}$ \\
\hline \multirow[t]{3}{*}{ Job role } & Employee & $66 \%$ & $66.3 \%$ \\
\hline & Self-employed & $21.2 \%$ & $5.3 \%$ \\
\hline & Other (e.g. collaborator) & $12.8 \%$ & $28.4 \%$ \\
\hline \multirow[t]{3}{*}{ Type of contract } & Full-time & $71.4 \%$ & $73.7 \%$ \\
\hline & Part-time & $28.6 \%$ & $25.7 \%$ \\
\hline & Missing & $0.0 \%$ & $0.6 \%$ \\
\hline \multirow[t]{5}{*}{ Type of contract } & Permanent & $54.7 \%$ & $60.3 \%$ \\
\hline & Fixed-Term & $14.3 \%$ & $10.3 \%$ \\
\hline & Any (e.g. VAT number) & $15.8 \%$ & $21 \%$ \\
\hline & Other & $11.3 \%$ & $8.1 \%$ \\
\hline & Missing & $3.9 \%$ & $0.3 \%$ \\
\hline \multirow[t]{6}{*}{ Schooling Level } & Primary school & $1.0 \%$ & $0.7 \%$ \\
\hline & Secondary school - 1st Grade & $11.3 \%$ & $14.3 \%$ \\
\hline & Secondary school - 2nd Grade & $43.8 \%$ & $47.3 \%$ \\
\hline & University - Bachelor Degree & $9.9 \%$ & $14 \%$ \\
\hline & University - Master Degree & $20.7 \%$ & $14.7 \%$ \\
\hline & Post-University & $13.3 \%$ & $9 \%$ \\
\hline \multirow[t]{3}{*}{ Study-work coherence* } & Yes & $51.2 \%$ & $47.7 \%$ \\
\hline & No & $36.5 \%$ & $39 \%$ \\
\hline & Not Applicable & $12.3 \%$ & $13.3 \%$ \\
\hline \multirow[t]{2}{*}{ Years of work } & Range & $0.5-42$ & $0.5-58$ \\
\hline & $\mathrm{M}(\mathrm{SD})$ & 13.14(10.64) & $17.60(12.22)$ \\
\hline \multirow[t]{2}{*}{ Hours of work per week } & Range & $3-70$ & $4-82$ \\
\hline & $\mathrm{M}(\mathrm{SD})$ & $38.11(13.47)$ & $37.91(11.83)$ \\
\hline \multirow[t]{3}{*}{ Work in days off } & Yes & $50.2 \%$ & $47.3 \%$ \\
\hline & No & $49.8 \%$ & $52.3 \%$ \\
\hline & Missing & $0.0 \%$ & $0.4 \%$ \\
\hline
\end{tabular}

Note. If the participant has a schooling level below Secondary School of 2nd grade, it is Not Applicable.

that addressed work addiction symptoms, obsessivecompulsive symptoms related to work, work-related perfectionism and work engagement. The participants have to indicate for each of the items if they agree with the sentences through a Likert scale ranging between 1 (Completely disagree) and 5 (Completely agree). Then, we administered the reduced version (10 items) of the test to the second sample of participants.

\subsubsection{Dutch Work Addiction Scale (DUWAS)}

The first sample of participants also filled the Italian short version of the Dutch Work Addiction Scale (DUWAS) [17], which may be downloaded from www.schaufeli.com. It is a 10-item self-report instrument that measures two dimensions of workaholism: Working Excessively and Working Compulsively. Referring to the total score, it can range between 10 and 40, since the participants fill the test using a 4point Likert scale ranging between 1 (Almost never) and 4 (Almost always).

\subsubsection{Utrecht Work Engagement Scale (UWES-9)}

The first sample of participants were also given the Italian version of the short form of the Utrecht Work Engagement Scale (UWES-9) [28], which may be downloaded from www.schaufeli.com. It is a 9-item self-report instrument measuring work engagement, and it comprehends three scales: Vigor, Dedication, and Absorption. However, Schaufeli, Bakker, and Salanova [17] recommend using the total score to measure work engagement. This instrument provides a 7 -point Likert scale $(0=$ Never and $6=$ Always, Every day), with the total score ranging between 0 and 54.

\subsection{Procedure}

After having requested authorization for conducting the research from the Ethical Committee of the Department of Health Sciences, we created a single online, web-based document. The online questionnaire contained some personal data (i.e., gender, age, 
region of living), followed by the pilot version of the Work-related Inventory (WI-36), the Dutch Work Addiction Scale (DUWAS), and the Utrecht Work Engagement Scale (UWES-9) for the first sample of participants. The second sample filled the personal data sheet and the WI-10 only.

We recruited participants via an announcement posted on Facebook, asking to help us spread the announcement as much as possible. We specified that we sought Italian workers to participate in a study about the psychometric properties of an instrument we were creating for evaluating work-related attitudes. We did not look for an organization that was interested in administering the questionnaire to its employees as we aimed to have a more heterogeneous sample concerning the type of job, job's role, and contract.

The rationale for the sample size was the following: 5 subjects for each item of the WI, that means that we needed at least 180 participants to run the Exploratory Factor Analysis and at least 50 participants for the Confirmatory Factor Analysis.

\subsection{Data analysis}

We conducted the analyses using SPSS.24 and AMOS.22. To reduce the number of items of the Work-related Inventory (WI-36), we conducted Exploratory Factor Analyses (EFA; Principal Axis Factoring and Varimax rotation) on the first sample of participants $(n=203)$ and Confirmatory Factor Analyses (CFA) on the second sample $(n=300)$. Then, we evaluated the convergent and divergent validity of the test through the analysis of the correlations (Pearson) between the reduced version of the WI, the DUWAS, and the UWES-9 $(n=203)$. We also calculated the internal reliability (Cronbach's alpha) and the itemtotal correlations of the scales on the total sample $(n=503)$. Finally, to establish the cut-off scores for high and low Workaholism/Work Engagement, we calculated the $T$ scores on the total sample $(n=503)$, and we selected the raw scores corresponding to \pm 1 standard deviation, that is the scores corresponding to the 40 and $60 T$ scores.

\section{Results}

\subsection{Factor structure}

First, we conducted some Exploratory Factor Analyses with Varimax rotation on the first sample $(n=203)$. We aimed to reduce the number of WI items (36 items in the pilot version) for obtaining a version of the test ranging between 8 and 15 items, to be used as a quick screening. We found the best solution for a 10-item and 2-factor model: Work Engagement and Workaholism. The first extracted factor explains $37.06 \%$ of the variance, while the second explains $20.84 \%$ of the variance, for a total variance explained of $57.9 \%$. Finally, all the items reach the recommended value of communality (i.e., 0.30 ), with values ranging between 0.30 (items 6 and 10) and 0.77 (item 4). Table 3 shows the saturation values of the two factors and the internal consistency of the two 5item scales, assessed by calculating Cronbach's alpha $(n=203)$.

Then we conducted some CFAs on the second sample $(n=300)$ for cross validation. The first CFA, which tested the two-factor model of the 10-item version of the test, showed a poor fit to the data: $\chi^{2}(34)=129.15, p<0.001$; Comparative Fit Index $(\mathrm{CFI})=0.90$; Goodness of Fit Index $(\mathrm{GFI})=0.92$; Tucker-Lewis Index (TLI) $=0.87$; Root Mean Square Error of Approximation $($ RMSEA) $=0.10$. However, after conducting other CFAs based on the deletion of some items (following modification indices suggestions), we found the best fit for an 8-item solution, in which we deleted item 1 from factor 1 (Work Engagement) and item 9 from factor 2 (Workaholism): $\chi^{2}(19)=53.47, p<0.001 ; \mathrm{CFI}=0.95 ; \mathrm{GFI}=0.96$; $\mathrm{TLI}=0.93$; RMSEA $=0.08$. The fit indexes are even better by allowing two pairs of errors to be correlated (i.e. error 6 with error 7, and error 6 with error 10): $\chi^{2}(17)=36.653, p=0.004 ; \mathrm{CFI}=0.97$; GFI $=0.97$; $\mathrm{TLI}=0.96$; RMSEA $=0.06$ (see Fig. 1 for a graphical representation of this model).

The internal reliability of the scales for this 8-item version is 0.83 (Work Engagement) and 0.63 (Workaholism), as evaluated on the total sample $(n=503)$. Moreover, the item-total correlations are high, ranging between 0.65 and 0.73 for the Workaholism scale, and between 0.71 and 0.89 for the Work Engagement scale $(n=503)$.

\subsection{Convergent and divergent validity}

Since the 8-item version of the WI-10 fits the data well, we referred to it for the following analyses on the psychometric properties of the WI-10 that we performed on the first sample of participants $(n=203)$. To assess the convergent and divergent validity of the WI-10, we examined the correlations between the WI-10 Workaholism and Work Engage- 
Table 3

Exploratory Factor Analysis (two factors, 10 items), $n=203$

\begin{tabular}{|c|c|c|}
\hline WI-10 Item & WE & $\overline{\mathrm{WH}}$ \\
\hline $\begin{array}{l}\text { 1. Mi piace lavorare più della maggior parte dei lavoratori } \\
\text { I like working more than most people do }\end{array}$ & 0.68 & \\
\hline $\begin{array}{l}\text { 2. A volte penso a come potrei passare più tempo a lavorare } \\
\text { Sometimes I think about how I could spend more time working }\end{array}$ & & 0.56 \\
\hline $\begin{array}{l}\text { 3. Nella mia vita, solo il lavoro mi dà le maggiori soddisfazioni } \\
\text { Only work provides me with the major fulfillment in my life }\end{array}$ & & 0.68 \\
\hline $\begin{array}{l}\text { 4. Di solito, trovo molto piacevole lavorare } \\
\text { Usually I find working very pleasurable }\end{array}$ & 0.86 & \\
\hline $\begin{array}{l}\text { 5. Spesso lavorare non sembra un dovere, perché è molto piacevole } \\
\text { Often working does not seem to be a duty because it is very enjoyable }\end{array}$ & 0.79 & \\
\hline $\begin{array}{l}\text { 6. Spesso, lavoro per ridurre sentimenti di colpa, ansia o depressione } \\
\text { Often I work in order to reduce feelings of guilt, anxiety, or depression }\end{array}$ & & 0.53 \\
\hline $\begin{array}{l}\text { 7. Penso costantemente al lavoro, anche durante le attività sociali } \\
\text { I think constantly about work, even during social activities }\end{array}$ & & 0.66 \\
\hline $\begin{array}{l}\text { 8. Mi sento energico mentre lavoro } \\
\text { Ifeel energetic while working }\end{array}$ & 0.70 & \\
\hline $\begin{array}{l}\text { 9. Sento un impulso interno a lavorare sempre di più } \\
\text { I feel an inner urge to work more and more }\end{array}$ & & 0.63 \\
\hline $\begin{array}{l}\text { 10. Sono soddisfatto di chi sono come lavoratore } \\
\text { I am satisfied with who I am as a worker }\end{array}$ & 0.55 & \\
\hline$\alpha$ & 0.62 & 0.61 \\
\hline
\end{tabular}

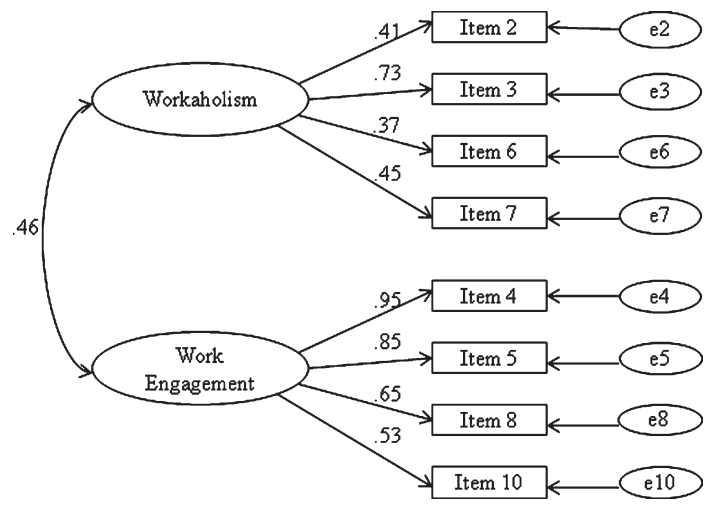

Fig. 1. Confirmatory Factor Analysis, WI-10. Two-factor Model, eight items, $n=300$. Note. $e=$ error; The correlations between errors are not represented. ment scales, the DUWAS total score and subscales (Working Excessively and Working Compulsively), and the UWES-9 total score. Table 4 shows the results of these correlation analyses.

\subsection{Cut-off scores for screening the four kinds of workers}

To establish the cut-off scores for high/low Workaholism and Work Engagement, we calculated the $T$ scores for the Workaholism and Work Engagement scales on the total sample $(n=503)$. Next, we looked for the raw scores corresponding to the $40 T$ score $(-1 \mathrm{SD})$ and the $60 T$ score (+1 SD). For Workaholism, we found the following scores: 5 and 10, which means that workers who score 4 have low

Table 4

Convergent and divergent validity of the WI-10 ( 8 items, 2 fillers; $n=203$ )

\begin{tabular}{lcccc}
\hline & DUWAS Tot & DUWAS WC & DUWAS WE & UWES-9 Tot \\
\hline WI-10 WH & $0.47^{*}$ & $0.47^{*}$ & $0.38^{*}$ & $0.28^{*}$ \\
WI-10 WE & 0.05 & 0.06 & 0.03 & $0.77^{*}$ \\
\hline
\end{tabular}

Note. $\mathrm{WI}-10=$ Work-related Inventory; $\mathrm{WH}=$ Workaholism scale; $\mathrm{WE}=$ Work Engagement scale; DUWAS $=$ Dutch Work Addiction Scale $; \mathrm{WC}=$ Working Compulsively scale $; \mathrm{WE}=$ Working Exces sively scale; UWES-9 = Utrecht Work Engagement Scale, Short form; $*=p<0.001$. 
Workaholism, while those scoring between 11 and 20 have high Workaholism. Concerning Work Engagement, we found 10 and 17, or people whose score is between 4 and 9 have low Work Engagement, while workers with a total score between 18 and 20 have high Work Engagement. See Table 5 for a graphical representation of the cut-off scores and Table 6 for a visual representation of the types of workers based on the suggested cut-off scores.

Referring to these cut-off scores, we identified 69 workers (13.7\%) with high Workaholism, 88 (17.5\%) with low Workaholism, 58 (11.5\%) with high Work Engagement, and $80(15.9 \%)$ with low Work Engagement. Moreover, we found that in our sample there were 2 (0.4\%) Disengaged Workaholics, 17 (3.4\%) Engaged Workaholics, $4(0.8 \%)$ Engaged workers, and 27 (5.4\%) Detached workers.

\section{Discussion}

In the literature, there are many instruments for evaluating workaholism. However, some studies showed that most of them do not have convergent validity $[18,19]$, which means that they could evaluate different phenomena. Loscalzo and Giannini [20] highlighted that this could be due to the lack of a shared definition, and based on a thorough review of the literature, proposed a comprehensive definition of workaholism that includes all the main components of the construct: addiction symptoms, obsessive-compulsive symptoms, and work engagement. They stated that also work engagement should be evaluated when measuring workaholism since workaholics could be characterized by either high or low level of work engagement. In line with this,

Table 5

Work-related Inventory (WI-10) cut-off scores

\begin{tabular}{lcc}
\hline & Workaholism Scale & Work Engagement Scale \\
\hline Low & 5 & 10 \\
High & 10 & 17 \\
\hline
\end{tabular}

Table 6

Profiling of the four types of workers by means of the Work-related Inventory (WI-10) and its cut-off scores

\begin{tabular}{lcc}
\hline Work Engagement & \multicolumn{2}{c}{ Workaholism score } \\
\cline { 2 - 3 } score & 4 (Low) & $11-20$ (High) \\
\hline $4-9$ (Low) & Detached worker & Disengaged Workaholic \\
$18-20$ (High) & Engaged worker & Engaged Workaholic \\
\hline
\end{tabular}

they stressed that when studying the antecedents and the outcomes of workaholism, we should distinguish between engaged workaholics and disengaged workaholics, since there could be some differences in the relationships.

This study, following Loscalzo and Giannini's [20] workaholism model and definition, aimed to propose a new comprehensive instrument, the Workrelated Inventory (WI-10), for assessing workaholism and screening four kinds of workers: Disengaged Workaholic, Engaged Workaholic, Engaged worker, Detached worker.

In the first stage, we developed a pool of 36 items covering addiction symptoms (core addiction components), obsessive-compulsive symptoms (including work-related perfectionism) and work engagement (including work enjoyment). Then, to reduce the number of items, we conducted some Exploratory Factor Analyses (EFAs), which showed a two-factor solution for a 10-item version of the WI-10: 1) Work Engagement; 2) Workaholism. However, the Confirmatory Factor Analysis (CFA) on the second sample of workers showed a poor fit for this model. The fit improved considerably by deleting two items (one for each factor) that we suggest to administer anyhow and to consider as filler items. Hence, we refer to the 8 -item version as the final WI- 10 .

It is interesting to note that, as far as the Workaholism scale is concerned, it does not include any item related to work-related perfectionism, since all of them have been deleted based on the EFA analysis. We speculate that this could be because perfectionism, and hence work-related perfectionism, is an antecedent of workaholism [30-32], and not a structural component of it.

Moreover, we would like to highlight that the final WI-10 version includes two Workaholism items that are similar to two BWAS [21] items, which evaluate problematic overworking referring to the addiction model (i.e., externalizing features). Our WI-10 item (i.e., Sometimes I think about how I could spend more time working) is similar in its content to the one included in the BWAS for assessing the salience component (i.e., How often during the last year have you ... Thought how to free up more time to work?). This item has proven to be problematic in the Italian version [33] of the Bergen Study Addiction Scale (BStAS) [34], which is the student's version of the BWAS and that has been created by replacing in the BWAS items the words related to work with terms related to study. However, Molino [35] found that the Italian BWAS has a good factor structure by means 
of both EFA and CFA analyses (and hence that this item is not problematic). Therefore, we conclude that this item adequately addresses the salience addiction component in the overworking context, while it is not satisfactory in the overstudying field. Hence, we suggest that this item is useful in the WI-10, as it allows a continuity with previous instruments that adopted the addiction model. Moreover, we posit that Workaholism and the constructs recently proposed for a similar condition in the educational field, namely Study Addiction [34] and Studyholism [36], are two different constructs. Even if overworking and overstudying might share some similarities, given that they are both related to the primary activity of workers and students, they deserve two different theorizations [36], as they might also have peculiar features.

The other WI-10 item similar to the BWAS is that used for evaluating the mood modification component. In this case, we would like to stress that we believe that this item, even if proposed by Andreassen et al. [21] in the addiction framework, might be used in both the addiction and obsessive framework. Also in the Obsessive Compulsive Disorder, people may enact a compulsion aiming to modify their negative mood. Again, this item allows to have continuity with previous assessment measures based on the addiction model; however, it is an item that encompasses both the addiction and obsession models. Hence, it is useful to have it in the WI-10, which is an instrument that refers to Loscalzo and Giannini [8] workaholism's definition as a construct comprehending both addiction and obsessive features.

As far as concern internal reliability, the values are satisfactory (the Cronbach's alpha values for Workaholism and Work Engagement are, respectively, 0.63 and 0.83). Even if the Cronbach's alpha is low for Workaholism, it should be noted that this value is based on four items only, which moreover cover different aspects of workaholism (addiction and obsession symptoms). Moreover, the item-total correlations of this scale are high (ranging between 0.65 and 0.73 ). Finally, this value reaches the cutoff of 0.60 for new scales [37]. The value for Work Engagement is instead high, coherently with the homogeneity of the items included in this factor.

In addition, the WI-10 showed good convergent and divergent validity. More specifically, the WI-10 Work Engagement scale has a high value of correlation (0.77) with the total score of the Utrecht Work Engagement Scale - Short form (UWES-9), while it has no significant correlation with both the total score and the two subscales of the Dutch Work Addiction Scale (DUWAS). Concerning the WI-10 Workaholism scale, it has good values of correlation with both the total score (0.47) and the two subscales of the DUWAS (Working Compulsively, 0.47; Working Excessively, 0.38). Hence, this shows that the WI-10 can evaluate both the cognitive and the behavioral components of workaholism. Moreover, the Workaholism scale has a low correlation (0.28) with the total score of the UWES-9. We believe that this result is in line with Loscalzo and Giannini's [8] proposal of considering workaholism and work engagement as two different constructs that, however, could be co-present, and hence that should be crossed to distinguish between Disengaged and Engaged Workaholics.

Finally, we established the cut-off scores for high and low Workaholism and Work Engagement, and we used these scores for analyzing how many workers, in our sample, had these different levels of work-related behaviors. Moreover, we crossed the two scales to screen for the four kinds of workers. We found that among our participants there are few Disengaged Workaholics and Engaged workers, but some Engaged Workaholics (3.4\%) and many Detached workers $(5.4 \%)$. The results showed that there are less Disengaged than Engaged Workaholics, also supporting the idea that workaholics could also be engaged in work, and that interventions which aim to reduce workaholism should take into account if the workaholic is also engaged or not in his/her work. Moreover, we found that there are many Detached workers, or people who are characterized by low levels of both Workaholism and Work Engagement, hence representing a problematic kind of worker that should receive intervention for improving both his/her health and the organization's productivity.

The main limitation of this study is due to the sample that, even if quite big and heterogeneous as far as job's role and contract are concerned, is not representative of all the Italian working population. Hence, this limits the generalizability of our results to workers of North and South Italy; future studies should evaluate if the factor structure we found on our sample of Central Italy workers fits the data well also with workers of other Italian regions.

\section{Conclusions}

This paper proposes a new and comprehensive instrument for evaluating workaholism that could 
help to clarify some aspects related to workaholism and work engagement since it allows measuring both the constructs with a short test. Moreover, to the best of our knowledge, it is the first instrument in the literature to have the cut-off scores for both high and low levels of Workaholism and Work Engagement, and that allows to screen for four kinds of worker: Disengaged Workaholic, Engaged Workaholic, Engaged worker, Detached worker. This will allow deepening the analysis of the different effects of disengaged and engaged workaholism on the organization, the worker and his/her family. Finally, it could also be useful for both preventive and clinical purposes.

Screening the workers of an organization and detecting if there are problematic work-related behaviors, such as low work engagement, high workaholism, or high detachment from work, could help developing interventions tailored on these people to favor their positive commitment to work and hence improving both their performance and their physical and psychological health. Finally, from a clinical perspective, the WI-10 allows to distinguish between different kinds of hard workers, avoiding to overpathologize a common behavior such as work, and to detect those workers that would benefit from an intervention aimed to decrease their workaholism and/or increase their engagement.

Detecting workaholics or workers at-risk of developing workaholism in the organizations is crucial, as the interventions aimed at decreasing workaholism and increasing work engagement are beneficial for the well-being of the worker and his/her family, but also for the productivity of his/her organization and the well-being of all the workers.

\section{Conflict of interest}

None to report.

\section{References}

[1] Ballone E, Valentino M, Occhiolini L, Di Mascio C, Cannone D, Shcioppa FS. Factors influencing psychological stress levels of Italian peacekeepers in Bosnia. Mil Med. 2000; 165:911-5.

[2] Loscalzo Y, Giannini M, Gori A, Di Fabio A. The Wellbeing of Italian Peacekeeper Military: Psychological Resources, Quality of Life and Internalizing Symptoms. Front Psychol. 2018;9:103.

[3] Niziurski JA, Bernsten, D. A prospective study of homesickness in soldiers during military development. Pers Individ Dif. 2018;120:81-6.
[4] Walsh J. Gender, the work-life interface and wellbeing: A study of hospital doctors. Gend Work Organ. 2013;20(4): 439-53.

[5] Ahmad W, Taggart F, Shafique MS, Muzafar Y, Abidi S, Ghani N, Malik Z, Zahid T, Waqas A, Ghaffar N. Diet, exercise and mental-wellbeing of healthcare professionals (doctors, dentists and nurses) in Pakistan. PeerJ. 2015;3:e1250.

[6] Hayes B, Prihodova L, Walsh G, Doyle F, Doherty S. What's up doc? A national cross-sectional study of psychological wellbeing of hospital doctors in Ireland. BMJ Open. 2017;7(10)

[7] Araújo AV, Arcanjo GS, Fernandes H, Arcanjo GS. Ergonomic work analysis: A case study of bus drivers in the private collective transportation sector. Work. 2018. In press.

[8] Essdai A, Spasojević Brkić VK, Golubović T, Brkić A, Popović V. Crane cabins' interior space multivariate anthropometric modeling. Work. 2018;59(4):557-70.

[9] West N, Snodgrass SJ, James C. The effect of load on biomechanics of the back and upper limb in a bench to shoulder lift during the WorkHab Functional Capacity Evaluation. Work. 2018;59(2):201-10.

[10] Saunders SL, MacEachen E, Nedelec B. Understanding and building upon effort to return to work for people with longterm disability and job loss. Work. 2015;52(1):103-14.

[11] Lorefice L, Fenu G, Frau J, Coghe GC, Marrosu MG, Cocco E. The impact of visible and invisible symptoms on employment status, work and social functioning in Multiple Sclerosis. Work. 2018. In press.

[12] Ohl A, Grice SM, Small S, Nguyen J, Paskor K, Zaniirian A. Predictors of employment status among adults with Autism Spectrum Disorder. Work. 2017;56(2):345-55.

[13] Oates W. Confession of a workaholic. New York, NY: Abingdon; 1997.

[14] Loscalzo Y, Giannini M. Workaholism: Cosa c'è di nuovo? [Workaholism: What's new?]. Counseling. 2015;8(3).

[15] Spence JT, Robbins AS. Workaholism - definition, measurement, and preliminary results. J Pers Assess. 1992;58:160-78.

[16] Robinson BE. Workaholism: Hidden legacies of adult children. Health Communications, Deerfield Beach, FL; 1989.

[17] Schaufeli WB, Shimazu A, Taris TW. Being driven to work excessively hard. The evaluation of a two-factor measure of workaholism in the Netherlands and Japan. Cross Cult Res. 2009; 43:320-48.

[18] Andreassen CS, Hetland J, Pallesen S. Psychometric assessment of workaholism measures. J Managerial Psychology. 2014;29(1):7-24.

[19] Patel AS, Bowler MC, Bowler JL, Methe SA. A metaanalysis of workaholism. Int J Bus Manag. 2012;7(11):2-17.

[20] Loscalzo Y, Giannini M. Clinical conceptualization of workaholism: A comprehensive model. Org Psychol Rev. 2017;7(4):306-29.

[21] Andreassen CS, Griffiths MD, Hetland J, Pallesen S. Development of a work addiction scale. Scand J Psychol. 2012;53:265-72.

[22] Kardefelt-Winther D. Commentary on: Are we overpathologizing everyday life? A tenable blueprint for behavioral addiction research. Problems with atheoretical and confirmatory research approaches in the study of behavioral addictions. J Behavioral Addictions. 2015;4(3):126-9.

[23] Van Beek I, Taris TW, Schaufeli WB. Workaholic and work engaged employees: Dead ringers or worlds apart? J Occup Health Psychol. 2011;16(4):468-82. 
[24] Kanai A, Wakabayashi M, Fling S. Workaholism among employees in Japanese corporations: An examination based on the Japanese version of the workaholism scales. Jpn Psychol Res. 1996;38:192-203.

[25] McMilan LHW, Brady EC, O’Driscoll MP, Marsch NV. A multifaceted validation study of Spence and Robbins' (1992) workaholism battery. J Occup Organ Psychol. 2002;75:357-68.

[26] Schaufeli WB, Salanova M, González-Romá V, Bakker AB. The measurement of engagement and burnout: A two sample confirmatory factor analytic approach. J Happiness Stud. 2002;3:71-92.

[27] Giannini M, Loscalzo Y. Workaholism: Health risk and prevention in the organizations. In: Di Fabio A., editor. Neuroticism: Characteristics, impact on job performance and health outcomes. New York: Nova Publisher; 2016. pp. 49-60.

[28] Schaufeli WB, Bakker AB. Utrecht Work Engagement Scale - Preliminary Manual, Version 1.1., December 2004. 2004; Unpublished data.

[29] Schaufeli WB, Bakker AB, Salanova M. The measurement of work engagement with a short questionnaire. Educ Psychol Meas. 2006;66:701-16.

[30] Falco A, Piccirelli A, Girardi D, Di Sipio A, De Carlo NA. "The best or nothing": The mediating role of workaholism in the relationship between perfectionism and burnout. TPM. 2014;21(2):213-32.
[31] Stoeber J, Davis CR, Townley J. Perfectionism and workaholism in employees: The role of work. Pers Individ Dif. 2013;55:733-8.

[32] Tziner A, Tanami M. Examining the links between attachment, perfectionism, and job motivation potential with job engagement and workaholism. J Work and Organizational Psychology. 2013;29:65-74.

[33] Loscalzo Y, Giannini M. The Bergen Study Addiction Scale: Psychometric properties of the Italian version. A pilot study. Psychiatria I Psychologia Kliniczna. 2018;18(3):271-5.

[34] Atroszko PA, Andreassen CL, Griffiths MD, Pallesen S. Study Addiction - A new area of psychological study: Conceptualization, assessment, and preliminary empirical findings. J Behav Addict. 2015;4(2):75-84.

[35] Molino M. Workaholism: Definitions, measures, and dynamics. PhD Thesis. 2012.

[36] Loscalzo Y, Giannini M. Studyholism or Study Addiction? A comprehensive model for a possible new clinical condition. In: Columbus AM, editor. Advances in Psychological Research. New York: Nova Publisher; 2017, pp. 19-37.

[37] Nunnaly JC, Bernstein IH. Psychometric Theory (3rd ed.). New York: McGraw-Hill; 1994. 